\title{
A novel histozoic myxosporean, Enteromyxum caesio n. sp., infecting the redbelly yellowtail fusilier, Caesio cuning, with the creation of the Enteromyxidae $n$. fam., to formally accommodate this commercially important genus
}

\author{
Mark A Freeman ${ }^{\text {Corresp., } 1}$, Tetsuya Yanagida ${ }^{2}$, Arni Kristmundsson ${ }^{3}$ \\ ${ }^{1}$ Department of Biomedical Sciences, Ross University School of Veterinary Medicine, Basseterre, Saint Kitts and Nevis \\ 2 Laboratory of Veterinary Parasitology, Joint Faculty of Veterinary Medicine, Yamaguchi University, Yoshida, Yamaguchi, Japan \\ 3 Institute for Experimental Pathology at Keldur, University of Iceland, Reykjavík, Iceland \\ Corresponding Author: Mark A Freeman \\ Email address: mafreeman@rossvet.edu.kn
}

Gastrointestinal myxosporean parasites from the genus Enteromyxum are known to cause severe disease, resulting in high mortalities in numerous species of cultured marine fishes globally. Originally described as Myxidium spp., they were transferred to a new genus, Enteromyxum, to emphasize their novel characteristics. Their retention in the family Myxidiidae at the time was warranted, but more comprehensive phylogenetic analyses have since demonstrated the need for a new family for these parasites. We discovered a novel Enteromyxum in wild fish from Malaysia and herein describe the fourth species in the genus and erect a new family, the Enteromyxidae $\mathrm{n}$. fam., to accommodate them. Enteromyxum caesio $\mathrm{n}$. sp. is described infecting the tissues of the stomach in the redbelly yellowtail fusilier, Caesio cuning, from Malaysia. The new species is distinct from all others in the genus, as the myxospores although morphologically similar, are significantly smaller in size. Furthermore, small subunit ribosomal DNA sequence data reveal that $E$. caesio is $<84 \%$ similar to others in the genus, but collectively they form a robust and discrete clade, the Enteromyxidae n. fam., which is placed as a sister taxon to other histozoic marine myxosporeans. In addition, we describe, using transmission electron microscopy, the epicellular stages of Enteromyxum fugu and show a scanning electron micrograph of a mature myxospore of $E$. caesio detailing the otherwise indistinct sutural line, features of the polar capsules and spore valve ridges. The Enteromyxidae $n$. fam. is a commercially important group of parasites infecting the gastrointestinal tract of marine fishes and the histozoic species can cause the disease enteromyxosis in intensive finfish aquaculture facilities. Epicellular and sloughed histozoic stages are responsible for fish-to-fish transmission in net pen aquaculture systems but actinospores from an annelid host are thought to be necessary for transmission to fish in the wild.

Peer) reviewing PDF | (2020:04:47505:1:2:NEW 3 Jun 2020) 
1 A novel histozoic myxosporean, Enteromyxum caesio

2 n. sp., infecting the redbelly yellowtail fusilier, Caesio

3 cuning, with the creation of the Enteromyxidae $\mathbf{n}$.

4 fam., to formally accommodate this commercially

5 important genus.

6

7

Mark Andrew Freeman ${ }^{1}$, Tetsuya Yanagida ${ }^{2}$, Árni Kristmundsson ${ }^{3}$

${ }^{1}$ Department of Biomedical Sciences, Ross University School of Veterinary Medicine, Basseterre, Saint Kitts and Nevis

${ }^{2}$ Laboratory of Veterinary Parasitology, Joint Faculty of Veterinary Medicine, Yamaguchi University, Yoshida, Yamaguchi, Japan

${ }^{3}$ Institute for Experimental Pathology at Keldur, University of Iceland, Reykjavík, Iceland

Corresponding Author:

Mark Freeman

PO Box 344 Basseterre, St. Kitts.

Email address: mafreeman@rossvet.edu.kn

\section{Abstract}

Gastrointestinal myxosporean parasites from the genus Enteromyxum are known to cause severe disease, resulting in high mortalities in numerous species of cultured marine fishes globally. Originally described as Myxidium spp., they were transferred to a new genus, Enteromyxum, to emphasize their novel characteristics. Their retention in the family Myxidiidae at the time was warranted, but more comprehensive phylogenetic analyses have since demonstrated the need for a new family for these parasites. We discovered a novel Enteromyxum in wild fish from Malaysia and herein describe the fourth species in the genus and erect a new family, the Enteromyxidae n. fam., to accommodate them.

Enteromyxum caesio n. sp. is described infecting the tissues of the stomach in the redbelly yellowtail fusilier, Caesio cuning, from Malaysia. The new species is distinct from all others in the genus, as the myxospores although morphologically similar, are significantly smaller in size. Furthermore, small subunit ribosomal DNA sequence data reveal that $E$. caesio is $<84 \%$ similar to others in the genus, but collectively they form a robust and discrete clade, the Enteromyxidae n. fam., which is placed as a sister taxon to other histozoic marine myxosporeans. In addition, we describe, using transmission electron microscopy, the epicellular stages of Enteromyxum fugu 
38

39

40

41

42

43

44

45

46

47

48

49

50

51

52

53

54

55

56

57

58

59

60

61

62

63

64

65

66

67

68

69

70

71

72

73

74

75

76

and show a scanning electron micrograph of a mature myxospore of $E$. caesio detailing the otherwise indistinct sutural line, features of the polar capsules and spore valve ridges.

The Enteromyxidae n. fam. is a commercially important group of parasites infecting the gastrointestinal tract of marine fishes and the histozoic species can cause the disease enteromyxosis in intensive finfish aquaculture facilities. Epicellular and sloughed histozoic stages are responsible for fish-to-fish transmission in net pen aquaculture systems but actinospores from an annelid host are thought to be necessary for transmission to fish in the wild.

\section{Introduction}

Myxosporeans from the genus Enteromyxum Palenzuela, Redondo et Alvarez-Pellitero, 2002, are all parasites of the gastrointestinal (GI) tract of marine fishes. Currently there are only three species described. The type species, Enteromyxum scophthalmi, was described from farmed turbot, Scophthalmus maximus, in the Mediterranean (Branson et al., 1999; Palenzuela et al., 2002), Enteromyxum leei was originally described from cultured sea bream Sparus aurata in Cyprus and Israel (Diamant et al., 1994), but is now known to infect multiple hosts (Padrós et al., 2001; Picard-Sánchez et al., 2020), and Enteromyxum fugu was described infecting tiger puffer, Takifugu rubripes, in Japan (Tin Tun et al., 2000). Both E. leei and E. fugu were originally placed in the genus Myxidium, due to similarities in spore morphology to some Myxidium spp. In the original description of Myxidium leei (syn. E. leei), Diamant et al. (1994) noted that the spore morphology did not convincingly match that of either Myxidium or Zschokkella, and his placement in Myxidium was therefore tentative. Since then, Palenzuela et al. (2002) and Yanagida et al. (2004) have used ribosomal DNA (rDNA) sequence data to demonstrate that $M$. leei and Myxidium fugu group together in a robust clade with E. scophthalmi and transferred both species to the genus Enteromyxum. It is now considered important to support myxosporean species descriptions with rDNA sequence data, as it has been widely demonstrated that some myxospore morphologies cannot be used to reliably place new myxosporean taxa correctly, with some spore morphotypes sharing features with other genetically distant clades within the Myxosporea (Freeman \& Kristmundsson, 2015). Enteromyxum leei and E. scophthalmi are serious pathogens in commercial fish farms, causing enteritis and emaciation disease, or enteromyxosis, resulting in high mortalities (Ogawa \& Yokoyama, 2001; Palenzuela et al., 2002; Sitjà-Bobadilla \& Palenzuela, 2012). Such disease outbreaks have led to the development of sensitive, non-invasive, molecular screening tools for use on farmed fish in order to help mitigate parasite numbers (Yanagida et al., 2005; Alonso et al., 2015). Reacting quickly to disease outbreaks and controlling parasite numbers is important with enteromyxosis, as fish to fish transmission is known to occur rapidly in fish farms (Diamant, 1997; Redondo et al., 2002; Yasuda et al., 2002; Picard-Sánchez et al., 2020), a phenomenon that is unique to Enteromyxum amongst the myxosporeans. 
77 The redbelly yellowtail fusilier, Caesio cuning (Bloch, 1791), is a tropical reef-associated fish

78 native to the Indian and Western Pacific Oceans. It inhabits coastal areas, usually over rocky

79 substrates and coral reefs, forming schools in mid-water feeding on zooplankton (Carpenter,

80 1987). They are a commercial species throughout most of their range, caught in traps and nets by

81 local fishers.

82 In the present study, we describe a fourth species that belongs to the genus Enteromyxum,

83 infecting the stomach of the redbelly yellowtail fusilier and erect a new family, the

84 Enteromyxidae n. fam., within the suborder Variisporina Lom et Noble, 1984 to accommodate

85 this distinctive myxosporean genus and complete its dissociation from the Myxidiidae sensu

86 stricto (s.s).

87

88

89

90

91

92

93

94

95

96

97

98

99

100

101

102

103

104

105

106

107

108

109

110

111

112

113

114 (Freeman et al., 2008).

\section{Materials \& Methods}

Five Caesio cuning were purchased from the fish market in Pulau Ketam near Port Klang, Selangor, three further $C$. cuning were bought from fishermen from Kilim mangroves [6² $46^{\prime} 55.36^{\prime \prime} \mathrm{N} ; 99^{\circ} 24^{\prime} 49.16^{\prime \prime} \mathrm{E}$, Langkawi, Malaysia. All fish were already dead when purchased and were examined as soon as possible for myxosporean parasites. The gastrointestinal GI tract was examined in sections, including the anterior stomach/ esophagus, stomach and intestine (anterior, middle and posterior/rectum), by scraping a dissected, saline-washed, tissue sample with a scalpel blade and viewing the preparation under a compound microscope. Images of fresh myxospores were taken using an Olympus CX21 microscope fitted with a Dino-Eye eyepiece camera (Dino-lite, UK). The dimensions of 30 myxospores were calculated using the imaging software package ImageJ (NIH, USA). Infected tissue samples were fixed in $10 \%$ buffered formalin for histological examination and GI scrapings, containing myxospores, fixed in $2.5 \%$ glutaraldehyde for scanning electron microscope (SEM) as previously described (Kristmundsson \& Freeman 2013). In addition, intestinal tissues from farmed Japanese tiger puffer, known to have a single intestinal myxosporean infection for the epicellular species Enteromyxum fugu, were prepared for transmission electron microscope (TEM) as previously described (Freeman \& Kristmundsson, 2013) and viewed on a Jeol JEM-1010 transmission electron microscope at Tokyo University.

Intestinal tissues scrapings containing myxospores were stored in lysis buffer from a GeneMATRIX DNA isolation kit (EURx Poland). Total DNA was extracted using the same kit following the tissue protocol. Small subunit ribosomal DNA (SSU rDNA) was amplified using the general myxosporean primers and methodology described by Freeman et al. (2008) with the addition of the new primer Ent-1100fwd 5'-AGAGTACTCACGCAAGTGAT-3', designed to be specific to this species of Enteromyxum only, and to be used with the reverse primer $18 \mathrm{gM}$

115 Positive PCR products were purified using a GeneMATRIX PCR products extraction kit (EURx 116 Poland). Bidirectional DNA sequencing was carried out on PCR products of the correct sizes, 
117 using the same primers, and nucleotide BLAST searches undertaken to confirm a parasitic 118 identity. The consensus sequence was obtained by eye using CLUSTAL X and BioEdit 119 (Thompson et al., 1997; Hall, 1999). CLUSTAL X was used for the initial SSU rDNA sequence 120 alignments of the novel sequence and 28 other myxosporeans. Percentage divergence matrices 121 were constructed from selected aligned taxa in CLUSTAL X using the neighbour-joining method 122 based on the Kimura 2-parameter model (Saitou and Nei, 1987). Phylogenetic analyses were performed using the maximum likelihood methodology in PhyML (Guindon et al., 2010) with the automatic smart model selection (selection criterion: Akaike Information Criterion (AIC)), running the general time-reversible substitution model (GTR +G6 +I) with 1000 bootstrap repeats. Bayesian inference (BI) analysis were done using MrBayes v. 3.2 (Ronquist \& Huelsenbeck, 2003). For the BI analysis, models of nucleotide substitution were generated using MrModeltest v. 2.2 (Nylander et al., 2004). The most suitable evolutionary model based on the Akaike information criterion was the general time-reversible model $(\mathrm{GTR}+\mathrm{I}+\mathrm{G})$. Therefore, settings used for the analysis were as previously noted by Kristmundsson \& Freeman (2013), with Chloromyxum riorajum (FJ624481) marked as the outgroup. Posterior probability distributions were created using the Markov Chain Monte Carlo (MCMC) method running four 134 simultaneous chains for one million generations.

The electronic version of this article in Portable Document Format (PDF) will represent a published work according to the International Commission on Zoological Nomenclature (ICZN), and hence the new names contained in the electronic version are effectively published under that Code from the electronic edition alone. This published work and the nomenclatural acts it contains have been registered in ZooBank, the online registration system for the ICZN. The ZooBank LSIDs (Life Science Identifiers) can be resolved and the associated information viewed through any standard web browser by appending the LSID to the prefix http://zoobank.org/. The LSID for this publication is: 1sid:zoobank.org:pub:A8A08CD0-7323-4F4D-A8A9E51FF86323CE, with the additional LSID identifiers for acts of nomenclature within the publication: 1sid:zoobank.org:act:676E54CE-BF4C-4CEE-BEF1-83EA20E88510 (Enteromyxidae n. fam.); 1sid:zoobank.org:act:AF828F1F-E6B9-4477-90FD-DE5C27CDE746 (Enteromyxum - Palenzuela, Redondo \& Alvarez-Pellitero, 2002); lsid:zoobank.org:act:2DE3D545-79D5-4D16-9932-2FC32E09E69E (Enteromyxum caesio $n$. sp.). The online version of this work is archived and available from the following digital repositories: PeerJ, PubMed Central and CLOCKSS.

\section{Results}

A total of 8 Caesio cuning were examined, total length (TL) 15-27 cm. Of five fish from Pulau Ketam, one fish (TL $18 \mathrm{~cm}$ ) was positive for a gastric myxosporean. From three fish in 
156 Langkawi, none were found to be infected. Therefore, only one fish from eight was infected by 157 this myxosporean.

158 Myxospores had curved outlines in both sutural and valvular view; mean length $9.0 \mu \mathrm{m}$ (range: $159 \quad 8.5-9.3 \mu \mathrm{m})$, width $5.7 \mu \mathrm{m}(5.0-6.3 \mu \mathrm{m})$, thickness $6.0 \mu \mathrm{m}$ (5.7-6.3) (Figs. $1 \& 2$; Table 1). In 160 valvular view they are lemon-shaped to ovoid with tips on each end and symmetrical along both 161 axes. The valves are identical, with nipple-like protrusions at the opposite end and side of the 162 spore, giving it a sigmoid appearance and a rotational symmetry $\left(180^{\circ}\right)$ in the sutural view (Fig. $1631 \& 2$ ). The spore valves lack striations (Fig. 3) but have a curved suture that bisects the spore 164 near the polar capsules. Two large elongate polar capsules (PC), mean size $4.6 \mu \mathrm{m}(4.3-4.9 \mu \mathrm{m})$ $165 \times 2.6 \mu \mathrm{m}(2.2-3.1 \mu \mathrm{m})$, lie at opposite ends of the spore, somewhat overlapping each other in the 166 valvular plane. Polar filaments have 7-9 coils and are discharged, in opposing directions, through the capsular foramina that are located at the pointed extremities of the spore valves. The sporoplasm is undivided and binucleate, filling most of the cavity surrounding the PC cells (Fig. $1)$. In histological section (Fig. 2A), large masses of disporous pseudoplasmodia were seen in what we assume to be the glandular part of the stomach wall, which had sloughed off post mortem, presumably as the fish were bought from a market and were fixed some hours after capture. Consequently, reliable description of host tissue response / pathology, associated with infections is not possible. SEM of myxospores confirm that the spore surfaces are smooth and not striated as in the Myxidiidae (s.s), with a non-conspicuous suture between the two valves (Fig. 3). Each valve has valvular projections or ridges adjacent to a terminal structure that houses the polar capsule (Fig. 3). TEM of a tiger puffer intestine infected with $E$. fugu shows developing epicellular stages of the parasite attached to the villi of the intestinal lining (Fig. 4). A single SSU rDNA consensus sequence of 1709 bp was successfully generated (GenBank accession number MT311171). BLAST searches revealed the highest identity matches were for the three currently described species of Enteromyxum, but only with an $83-84 \%$ similarity (Table 2). Phylogenetic analyses of myxosporeans representing the main marine clades, robustly grouped E. caesio with the other three species of Enteromyxum, irrespective of the phylogenetic methodology used (Fig. 5).

185

Taxonomic summary:

189

Class Myxozoa Grassé, 1970

Subclass Myxosporea Bütschli, 1881

Order Bivalvulida Shulman, 1959

195

Suborder Variisporina Lom et Noble, 1984 
196 Enteromyxidae n. fam. Freeman, Yanagida et Kristmundsson, 2020

197

198

199

200

201

202

203

204

205

206

207

208

209

210

211

212

213

214

215

216

217

218

219

220

221

222

223

224

225

226

227

228

229

230

231

232

233

234

235

Maintaining characteristics of the generic description of Palenzuela et al. (2002), updated to include epicellular forms and infection of the glandular tissues of the stomach.

Histozoic, sometimes epicellular or with epicellular stages, parasites of the intestinal epithelium or gastric glandular tissues of the digestive system of marine fishes. Causes acute enteritis, cachexia and death in susceptible fish, entirely epicellular species are not pathogenic.

Myxospores with slightly crescent shape, relatively large and elongated polar capsules tapering to their distal side and opening at the ends of the spore but discharging in opposite directions relative to a longitudinal plane bisecting the spore in top or bottom view. One binucleated sporoplasm. Spores develop in disporic pansporoblasts.

Single genus: Enteromyxum (Palenzuela, Redondo et Alvarez-Pellitero, 2002)

Type species. Enteromyxum scophthalmi (Palenzuela, Redondo et Alvarez-Pellitero, 2002)

Type host. Scophthalmus maximus (Linnaeus, 1758)

Enteromyxum caesio $\mathrm{n}$. sp. Freeman, Yanagida et Kristmundsson, 2020

Type locality: Pulau Ketam, Peninsular Malaysia [3 5'35.98"N; 101¹4'34.17"E]

Type host: Caesio cuning (Bloch, 1791)

Site of infection: histozoic in the stomach wall, likely in the glandular tissues

Etymology: caesio refers to the scientific name of the host.

Type material: a 1709 bp SSU rDNA sequence with the accession number MT311171 has been submitted to NCBI.

\section{Discussion}

It has been previously demonstrated with independent molecular phylogenetic analyses that Enteromyxum spp. form a monophyletic clade within the marine myxosporeans that is distinct from members of the genus Myxidium (Palenzuela et al., 2002; Yanagida et al., 2004; Fiala et al., 2015). Furthermore, it has been demonstrated that the histozoic genera Enteromyxum, Gastromyxum and Monomyxum form separate but robustly supported clades that allowed the creation of two new families Gastromyxidae Freeman et Kristmundsson, 2015, and Monomyxidae Freeman et Kristmundsson, 2015, to accommodate Gastromyxum spp. and Monomyxum spp. respectively (Freeman \& Kristmundsson, 2015). It was also stated, by Freeman \& Kristmundsson (2015), that the placement of Enteromyxum in the family Myxidiidae was not considered correct and that a new family was warranted for the genus. As such, we have created a new family, Enteromyxidae n. fam., to accommodate this distinctive and important genus of myxosporean parasites and described the fourth species. 
237

238

239

240

241

242

243

244

245

246

247

248

249

250

251

252

253

254

255

256

257

258

259

260

261

262

263

264

265

266

267

268

269

270

271

272

273

274 There are reports that some species of Enteromyxum are epicellular (Tin Tun et al., 2002;

275 Yanagida et al., 2004; Cuadrado et al., 2007), and developing trophozoites are clearly seen

Enteromyxum share some similarities to Gastromyxum such as smooth valves with an indistinct suture bisecting the spore with a similar overall morphology, and both are histozoic in the digestive tracts of marine fishes. However, notable differences also exist, with respect to the size and extent on the polar capsules and the pathogenic nature of Enteromyxum compared to Gastromyxum, although Gastromyxum could potentially become pathogenic in an aquaculture setting. Perhaps the most significant and consistent difference between these genera is their reproducible placement within phylogenetic analyses of marine myxosporeans as robustly supported but separate clades (Freeman \& Kristmundsson, 2015; Casal et al., 2019; present study). This remains the primary reason that this genus requires a distinct family as inclusion in the Gastromyxidae would create unacceptable paraphyly in what is a robust section of the phylogeny of histozoic marine myxosporeans. Although the relationship between the histozoic genera Enteromyxum, Gastromyxum and Monomyxum is consistently recovered as basal to the kudoids (Freeman \& Kristmundsson, 2015; Casal et al., 2019), their relationship between other robust histozoic clades within the marine myxosporeans, such as the Ceratonova clade, are not always retrieved (Fiala et al., 2015). These inconsistencies make the higher-level grouping of such clades unreliable; until additional sequences are uncovered that allow such relationships to be more consistently demonstrated.

The overall myxospore morphology of E. caesio n. sp. is typical of those from the genus; however, the actual spore size is much smaller than those previously described (Table 1). Using myxospore morphology for diagnosis could result in confusion between other genera that are phylogenetically distinct but found in the digestive tract of marine fish, such as Sigmomyxa, Gastromyxum or some Myxidium spp., therefore, identification using molecular techniques is the preferred method to support initial diagnosis, especially considering the potential impact of Enteromyxum spp. to farmed marine fish.

Although myxospore morphology is well conserved within the Enteromyxum clade, the four described species are genetically divergent sharing only between $82.2 \%-88.7 \%$ identity to each other with respect to SSU rDNA sequences. This phenomenon has been reported before, where a robustly supported clade of myxosporeans, the Paramyxidium, has a highly conserved myxospore morphology but a broad genetic diversity (Freeman \& Kristmundsson, 2018). For the Paramyxidium, it has been suggested that this is due to a significant under-sampling of species within the genus/clade and that many more members of the Paramyxidium will be uncovered with more extensive molecular sampling (Fiala et al., 2019). This, along with the discovery of $E$. caesio, suggests that there could be many more species of Enteromyxum that are as yet undescribed, infecting wild fish that could impact the globally expanding marine finfish aquaculture industry.

Peer) reviewing PDF | (2020:04:47505:1:2:NEW 3 Jun 2020) 
276

277

278

279

280

281

282

283

284

285

286

287

288

289

290

291

292

293

294

295

296

297

298

299

300

301

302

303

304

305

306

307

308

309

310

311

312

313

314

attached to the intestinal villi via pseudopodia in $E$. fugu (Fig. 4). True epicellular species are not thought to cause the clinical signs of enteromyxosis, but any detached or sloughed off epicellular forms are likely to cause fish-to-fish transmission in intensive net pen aquaculture systems, albeit benign. In advanced histozoic infections of E. leei, fish develop enteritis and liquid filled intestines (Sitjà-Bobadilla \& Palenzuela, 2012). During the excretion of such material, extensive sloughing of the intestinal wall is likely which leads to the release of developing histozoic stages into the environment. In intensive finfish culture, these stages are transmitted to cohabiting uninfected fish in the same cage and develop to cause the clinical signs of enteromyxosis (Picard-Sánchez et al., 2020). Mixed infections of histozoic species, like E. leei, with epicellular E. fugu and an unidentified epicellular myxosporean have been reported in aquaculture settings, but the histozoic species alone are considered to cause disease (Yanagida et al., 2005; Cuadrado et al., 2007).

Myxosporean stages were also observed in fresh smears or mucosal scrapings or in the fluid present in the digestive lumen of farmed turbot with clinical signs of disease (Branston et al., 1999). Branston et al. (1999) also noted that the primary infection might be caused by a waterborne actinospore, as there was a random pattern of initial disease occurrence throughout affected farms. However, once infection was established the disease spreads rapidly, with 100\% mortality in all tanks where it was first diagnosed, again suggesting rapid fish-to-fish transmission within the same tank. In our phylogenetic tree, there is a DNA sequence from actinospores released from a marine polychaete in Portugal (Rangel et al., 2011) that groups within the Enteromyxum clade and has typical inter species genetic variation for the genus (Table 2 ), suggesting that typical transmission to fish in this genus is via an actinospore.

\section{Conclusions}

Herein, we have described a fourth species of Enteromyxum, E. caesio n. sp., and demonstrated the necessity for a new family, the Enteromyxidae n. fam., to accommodate this distinct and important genus of myxosporeans. Members of the Enteromyxidae n. fam. are parasites of the gastrointestinal tract of marine fishes and histozoic species can cause the disease enteromyxosis in intensive finfish aquaculture facilities. The Enteromyxidae n. fam. are phylogenetically related to other histozoic myxosporeans from the marine environment, but remain a discreet group. Within the Enteromyxidae $\mathrm{n}$. fam., there is a significant genetic range with respect to SSU rDNA sequence data, and it is expected that numerous other species in this family are yet to be discovered.

\section{References}


315 Alonso M, Lago FC, Gómez-Reino M, Fernández Casal J, Martín Varela I, Vieites JM, Espiñeira 316 M. (2015) Non-invasive fast real-time PCR assay for detection of the enteric parasite

317 Enteromyxum scophthalmi in cultured turbot (Scophthalmus maximus L.). Aquaculture Research, 318 46, 2104-2115. https://doi.org/10.1111/are.12366

319

320

321

322

323

324

325

326

327

328

329

330

331

332

333

334

335

336

337

338

339

340

341

342

343

344

345

346

347

348

349

350

351

352

Branson E, Riaza A, Alvarez-Pellitero P. (1999) Myxosporean infection causing intestinal disease in farmed turbot, Scophthalmus maximus (L.), (Teleostei: Scophthalmidae). Journal of Fish Diseases, 22, 395-399. https://doi.org/10.1046/j.1365-2761.1999.00193.x

Carpenter KE. (1987) Revision of the Indo-Pacific fish family Caesionidae (Lutjanoidea), with descriptions of five new species. Indo-Pacific Fishes, 15, 1-56.

Casal G, Soares EC, Rocha S, Silva TJ, Santos EL, Nascimento R, Oliveira E, Azevedo C. (2019) Description of a new myxozoan Kudoa eugerres n. sp. and reclassification of two Sphaerospora sensu lato species. Parasitology Research, 118, 1719-1730.

https://doi.org/10.1007/s00436-019-06324-8

Cuadrado M, Albinyana G, Padrós F, Redondo MJ, Sitjà-Bobadilla A, Alvarez-Pellitero P, Palenzuela O, Diamant A, Crespo S. (2007) An unidentified epi-epithelial myxosporean in the intestine of gilthead sea bream Sparus aurata L. Parasitology Research, 101, 403-411. https://doi.org/10.1007/s00436-007-0484-0

Diamant A. (1997) Fish-to-fish transmission of a marine myxosporean. Diseases of Aquatic Organisms, 30, 99-105.

Diamant A. (1998) Red drum Sciaenops ocellatus (Sciaenidae), a recent introduction to Mediterranean mariculture, is susceptible to Myxidium leei (Myxosporea). Aquaculture 162, 3339.

Diamant A, Lom J, Dyková I. (1994) Myxidium leei n. sp., a pathogenic myxosporean of cultured sea bream Sparus aurata. Diseases of Aquatic Organisms, 20, 137-141.

Fiala I, Hlavničková M, Kodádková A, Freeman MA, Bartošová-Sojková P, Atkinson SD. (2015) Evolutionary origin of Ceratonova shasta and phylogeny of the marine myxosporean lineage. Molecular Phylogenetic and Evolution, 86, 75-89.

https://doi.org/10.1016/j.ympev.2015.03.004.

Peer) reviewing PDF | (2020:04:47505:1:2:NEW 3 Jun 2020) 
353 Fiala I, Lisnerová M, Baiko D, Blabolil P, Lövy A, Holzer A. (2019) Hidden diversity of 354 Paramyxidium (Myxozoa) species in European eel (Anguilla anguilla). [Abstract 224-O] EAFP 355 Porto Portugal: 231

356

357

358

359

360

361

362

363

364

365

366

367

368

369

370

371

372

373

374

375

376

377

378

379

380

381

382

383

384

385

386

387

388

389

390

391

392

Freeman MA, Kristmundsson Á. (2013) Ultrastructure of Nucleospora cyclopteri, an intranuclear microsporidian infecting the Atlantic lumpfish (Cyclopterus lumpus L.). BulletinEuropean Association of Fish Pathologists, 33,194-198.

Freeman MA, Kristmundsson Á. (2015) Histozoic myxosporeans infecting the stomach wall of elopiform fishes represent a novel lineage, the Gastromyxidae. Parasites \& Vectors, 8, 517. https://doi.org/10.1186/s13071-015-1140-7

Freeman MA, Kristmundsson Á. (2018) Studies of Myxidium giardi Cépède, 1906 infections in Icelandic eels identifies a genetically diverse clade of myxosporeans that represents the Paramyxidium n. g. (Myxosporea: Myxidiidae). Parasites \& Vectors, 11, 551. https://doi.org/10.1186/s13071-018-3087-y

Freeman MA, Yokoyama H, Ogawa K. (2008) Description and phylogeny of Ceratomyxa anko sp. n. and Zschokkella lophii sp. n. from the Japanese anglerfish, Lophius litulon (Jordan).

Journal of Fish Diseases. 31, 921-30. https://doi.org/10.1111/j.1365-2761.2008.00965.x.

Guindon S, Dufayard JF, Lefort V, Anisimov M, Hordijk W, Gascuel O. (2010) New algorithms and methods to estimate maximum-likelihood phylogenies: assessing the performance of PhyML 3.0. Systematic Biology, 59, 307-321. https://doi.org/10.1093/sysbio/syq010.

Hall TA. (1999) BioEdit: a user-friendly biological sequence alignment editor and analysis program for Windows 95/98/ NT. Nucleic Acids Symposium Series, 41, 95-98.

Le Breton A, Marques A. (1995) Occurrence of an histozoic Myxidium infection in 2 marine cultured species: Puntazzo puntazzo C. and Pagrus major. Bulletin-European Association of Fish Pathologists, 15, 210-212.

Kristmundsson Á, Freeman MA. (2013) Sphaeromyxids form part of a diverse group of myxosporeans infecting the hepatic biliary systems of a wide range of host organisms. Parasites \& Vectors, 6, 51. https://doi.org/10.1186/1756-3305-6-51

Nylander JAA, Ronquist F, Huelsenbeck JP, Nieves-Aldrey JL. (2004) Bayesian phylogenetic analysis of combined data. Systematic Biology, 53, 47-67.

https://doi.org/10.1080/10635150490264699

Peerj reviewing PDF | (2020:04:47505:1:2:NEW 3 Jun 2020) 
393 Ogawa K, Yokoyama H. (2001) Emaciation disease of cultured tiger puffer Takifugu rubripes. 394 Bulletin of National Research Institute of Aquaculture, (Suppl), 5, 65-70.

395

396

397

398

399

400

401

402

403

404

405

406

407

408

409

410

411

412

413

414

415

416

417

418

419

420

421

422

423

424

425

426

427

428

429

430

431

432

Padrós F, Palenzuela O, Hispano C, Tosas O, Zaraza C, Crespo S, Álvarez-Pellitero P. (2001) Myxidium leei (Myxozoa) infections in aquarium-reared Mediterranean fish species. Diseases of Aquatic Organisms, 47, 57-62. https://doi.org/10.3354/dao047057

Palenzuela O, Redondo MJ, Alvarez-Pellitero P. (2002) Description of Enteromyxum scophthalmi gen. nov., sp. nov. (Myxozoa), an intestinal parasite of turbot (Scophthalmus maximus L.) using morphological and ribosomal RNA sequence data. Parasitology, 124, 369379. https://doi.org/10.1017/S0031182001001354

Picard-Sánchez A, Estensoro I, Del Pozo R, Palenzuela OR, Piazzon MC, Sitjà-Bobadilla A. (2020) Water temperature, time of exposure and population density are key parameters in Enteromyxum leei fish-to-fish experimental transmission. Journal of Fish Diseases, 43, 491502. https://doi.org/10.1111/jfd.13147

Rangel LF, Cech G, Székely C, Santos MJ. (2011) A new actinospore type, Unicapsulactinomyxon (Myxozoa), infecting the marine polychaete, Diopatra neapolitana (Polychaeta: Onuphidae) in the Aveiro Estuary (Portugal). Parasitology, 138, 698-712. https://doi.org/10.1017/S0031182011000163

Redondo MJ, Palenzuela O, Riaza A, Macias A, Álvarez-Pellitero P. (2002) Experimental transmission of Enteromyxum scophthalmi (Myxozoa), an enteric parasite of turbot Scophthalmus maximus. Journal of Parasitology, 88, 482-488. https://doi.org/10.1645/00223395(2002)088[0482:ETOESM]2.0.CO;2

Ronquist F, Huelsenbeck JP. (2003) MrBayes 3: Bayesian phylogenetic inference under mixed models. Bioinformatics, 19, 1572-1574. https://doi.org/10.1093/bioinformatics/btg180

Saitou N, Nei M. (1987) The neighbour-joining method: a new method for reconstructing phylogenetic trees. Molecular Biology and Evolution, 4, 406-425.

Sitjà-Bobadilla A, Palenzuela O. (2012) Enteromyxum species. In: Woo PTK \& Buchmann K, eds. Fish Parasites: Pathology and Protection. Denmark: CAB International, Oxfordshire UK, 163-176.

Tin Tun, Yokoyama H, Ogawa K Wakabayashi H. (2000) Myxosporeans and their hyperparasitic microsporeans in the intestine of emaciated tiger puffer. Fish Pathology, 35, 145156. https://doi.org/10.3147/jsfp.35.145

Peer] reviewing PDF | (2020:04:47505:1:2:NEW 3 Jun 2020) 
433

434 Thompson JD, Gibson TJ, Plewniak F, Jeanmougin F, Higgins DG. (1997) The CLUSTAL-X

435 windows interface: flexible strategies for multiple sequence alignment aided by quality analysis

436 tools. Nucleic Acids Research, 24, 4876-4882. https://doi.org/10.1093/nar/25.24.4876

437

438 Yanagida T, Nomura Y, Kimura T, Fukuda Y, Yokoyama H, Ogawa K. (2004) Molecular and 439 morphological redescriptions of enteric myxozoans, Enteromyxum leei (formerly Myxidium sp.

$440 \mathrm{TP}$ ) and Enteromyxum fugu comb. n. (syn. Myxidium fugu) from cultured tiger puffer. Fish

441 Pathology, 39, 137-143. https://doi.org/10.3147/jsfp.39.137

442

443 Yanagida T, Freeman MA, Nomura Y, Takami I, Sugihara Y, Yokoyama H, Ogawa K. (2005)

444 Development of a PCR-based method for the detection of enteric myxozoans causing the

445 emaciation disease of cultured tiger puffer. Fish Pathology, 40, 23-28.

446 https://doi.org/10.3147/jsfp.40.23

447

448 Yasuda H, Ooyama T, Iwata K, Tin Tun, Yokoyama H, Ogawa K. (2002) Fish-to-fish

449 transmission of Myxidium spp. (Myxozoa) in cultured tiger puffer suffering from emaciation

450 disease. Fish Pathology, 37, 29-33. https://doi.org/10.3147/jsfp.37.29

451 


\section{Table $\mathbf{1}$ (on next page)}

Myxospore dimensions reported from Enteromyxum spp. 
Table 1:

Myxospore dimensions reported for Enteromyxum spp.

\begin{tabular}{|c|c|c|c|c|c|c|c|c|}
\hline \multirow[b]{2}{*}{$\begin{array}{c}\text { Myxozoan } \\
\text { species }\end{array}$} & \multirow[b]{2}{*}{$\begin{array}{c}\text { Fish } \\
\text { host } / \text { s }\end{array}$} & \multicolumn{3}{|c|}{ "Spore dimensions $(\mu \mathrm{m})$} & \multicolumn{3}{|c|}{ Polar capsules $(\mu \mathrm{m})$} & \multirow[b]{2}{*}{ Reference } \\
\hline & & $\begin{array}{l}\text { Mean } \\
\text { length } \\
\text { (Range) }\end{array}$ & $\begin{array}{c}\text { Mean } \\
\text { width } \\
\text { (Range) }\end{array}$ & $\begin{array}{c}\text { Mean } \\
\text { thickness } \\
\text { (Range) }\end{array}$ & $\begin{array}{l}\text { Mean } \\
\text { length } \\
\text { (Range) }\end{array}$ & $\begin{array}{c}\text { Mean } \\
\text { width } \\
\text { (Range) }\end{array}$ & $\begin{array}{l}\text { Number } \\
\text { of coils }\end{array}$ & \\
\hline \multirow{3}{*}{$\begin{array}{l}\text { Enteromyxum } \\
\text { leei }\end{array}$} & Sparus aurata & $\begin{array}{c}14.7 \\
(13.2-15.2)\end{array}$ & $\begin{array}{c}6.9 \\
(5.6-7.8)\end{array}$ & 6 & $\begin{array}{c}7.4 \\
(6.2-8.8)\end{array}$ & $\begin{array}{c}3.2 \\
(2.8-3.8)\end{array}$ & $\begin{array}{c}7 \\
(6-8)\end{array}$ & Diamant et al. (1994) \\
\hline & Diplodus puntazzo & $(15-19)$ & $(5-7)$ & n.d. & $6.5-9.0$ & $2.5-4.0$ & n.d. & LeBreton \& Marques (1995) \\
\hline & Sciaenops ocellatus & $\begin{array}{c}17.5 \\
(15.5-19.5)\end{array}$ & $\begin{array}{c}7.4 \\
(7.0-8.7) \\
\end{array}$ & n.d. & $\begin{array}{c}8.4 \\
(7.0-9.8) \\
\end{array}$ & $\begin{array}{c}3.8 \\
(3.3-4.5)\end{array}$ & n.d. & Diamant (1998) \\
\hline $\begin{array}{l}\text { Enteromyxum } \\
\text { fugu }\end{array}$ & Takifugu rubripes & $\begin{array}{c}14.4 \\
(13.5-15.5)\end{array}$ & $\begin{array}{c}9.0 \\
(8.0-10.0) \\
\end{array}$ & n.d. & $\begin{array}{c}6.1 \\
(5.0-7.5) \\
\end{array}$ & $\begin{array}{c}2.2 \\
(2.0-3.0) \\
\end{array}$ & n.d. & Tin Tun et al. (2000) \\
\hline $\begin{array}{l}\text { Enteromyxum } \\
\text { scophthalmi }\end{array}$ & $\begin{array}{l}\text { Scophthalmus } \\
\text { maximus }\end{array}$ & $\begin{array}{c}22.2 \\
(20-25)\end{array}$ & $\begin{array}{c}11.7 \\
(9.2-14.1)\end{array}$ & 14 & $\begin{array}{c}10.4 \\
(8.6-13.0)\end{array}$ & $\begin{array}{c}4.6 \\
(3.6-6.0)\end{array}$ & 11 & Palenzuela et al. (2002) \\
\hline $\begin{array}{l}\text { Enteromyxum } \\
\text { caesio } \mathrm{n} . \mathrm{sp} .\end{array}$ & Caesio cuning & $\begin{array}{c}9.0 \\
(8.5-9.3) \\
\end{array}$ & $\begin{array}{c}5.7 \\
(5.0-6.3) \\
\end{array}$ & $\begin{array}{c}6.0 \\
(5.7-6.3) \\
\end{array}$ & $\begin{array}{c}4.6 \\
(4.3-4.9) \\
\end{array}$ & $\begin{array}{c}2.6 \\
(4.1-4.9) \\
\end{array}$ & $\begin{array}{c}8 \\
(7-9) \\
\end{array}$ & Present study \\
\hline
\end{tabular}




\section{Table 2 (on next page)}

Percentage identities of SSU rDNA sequences from the Enteromyxum clade (Fig. 5) above diagonal, and number of bases compared, below diagonal. 
1

2 Table 2:

3 Percentage identities of SSU rDNA sequences from the Enteromyxum clade (Fig. 5) above

4 diagonal, and number of bases compared, below diagonal.

\begin{tabular}{lccccc}
\hline Enteromyxum caesio $\mathrm{n} . \mathrm{sp}$. & - & 82.29 & 82.15 & 83.66 & 79.07 \\
Enteromyxum scophthalmi & 1572 & - & 86.40 & 88.65 & 84.58 \\
Enteromyxum leei & 1569 & 1573 & - & 84.31 & 83.03 \\
Enteromyxum fugu & 1499 & 1506 & 1491 & - & 85.01 \\
Unicapsulactinomyxon & 994 & 999 & 990 & 994 & - \\
\hline
\end{tabular}

5 


\section{Figure 1}

Line drawings of myxospores of Enteromyxum caesio n. sp .

(A) Spore shown in the sutural view. (B) Spore shown in valvular view. Position of the suture is shown with a dashed line, scale bar $=5 \mu \mathrm{m}$. 

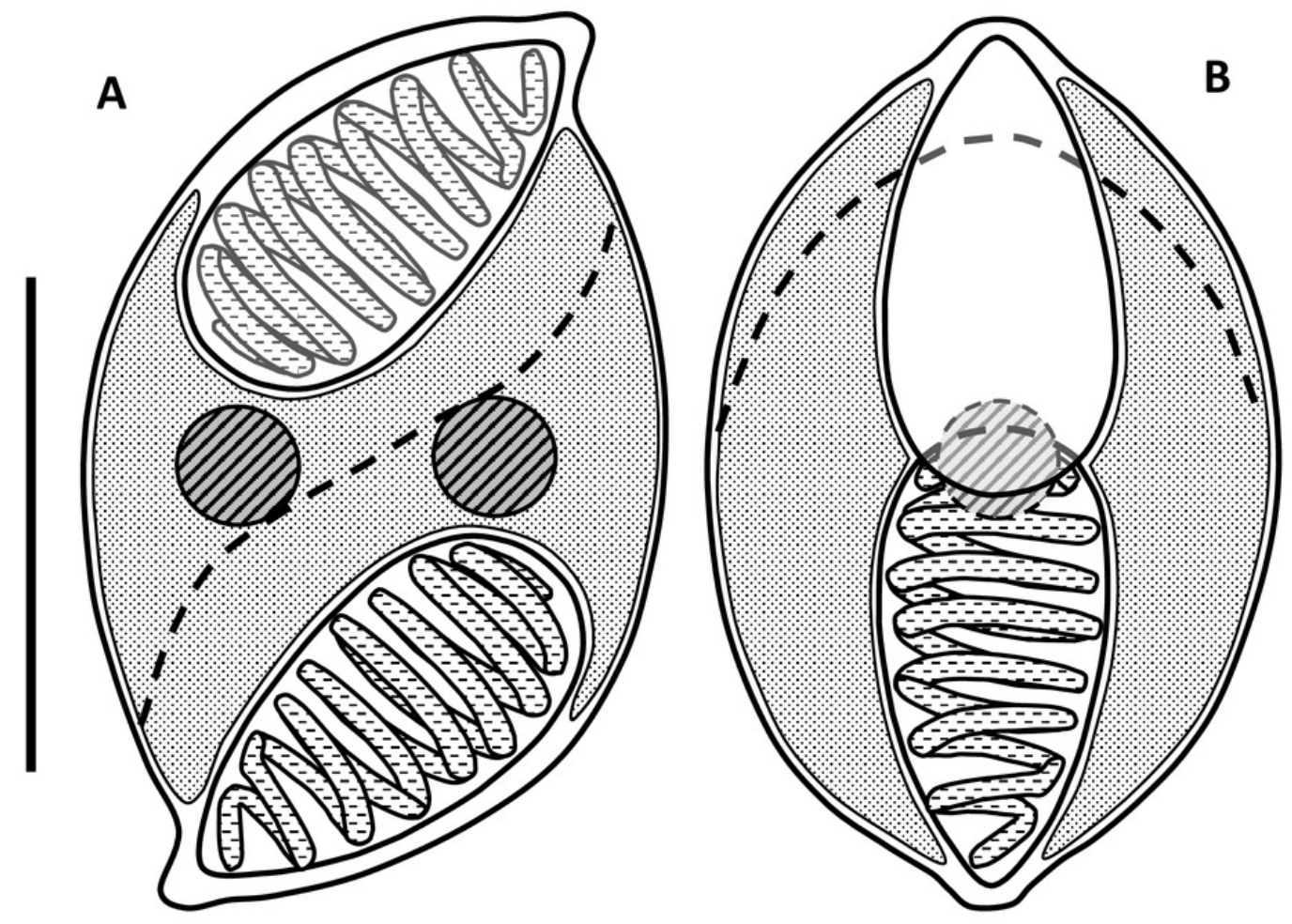
Figure 2

Myxospores of Enteromyxum caesio n. sp.

(A) Giemsa stained histological section from the stomach of Caesio cuning, detailing a large mass of disporous pseudoplasmodia of E. caesio n. sp. (B) Fresh spore in sutural view. (C \& D) Disporous pseudoplasmodia showing the variation in spore morphologies seen dependent on the plane of focus. Scale bars $A=30 \mu \mathrm{m}, \mathrm{B}-\mathrm{D}=10 \mu \mathrm{m}$. 

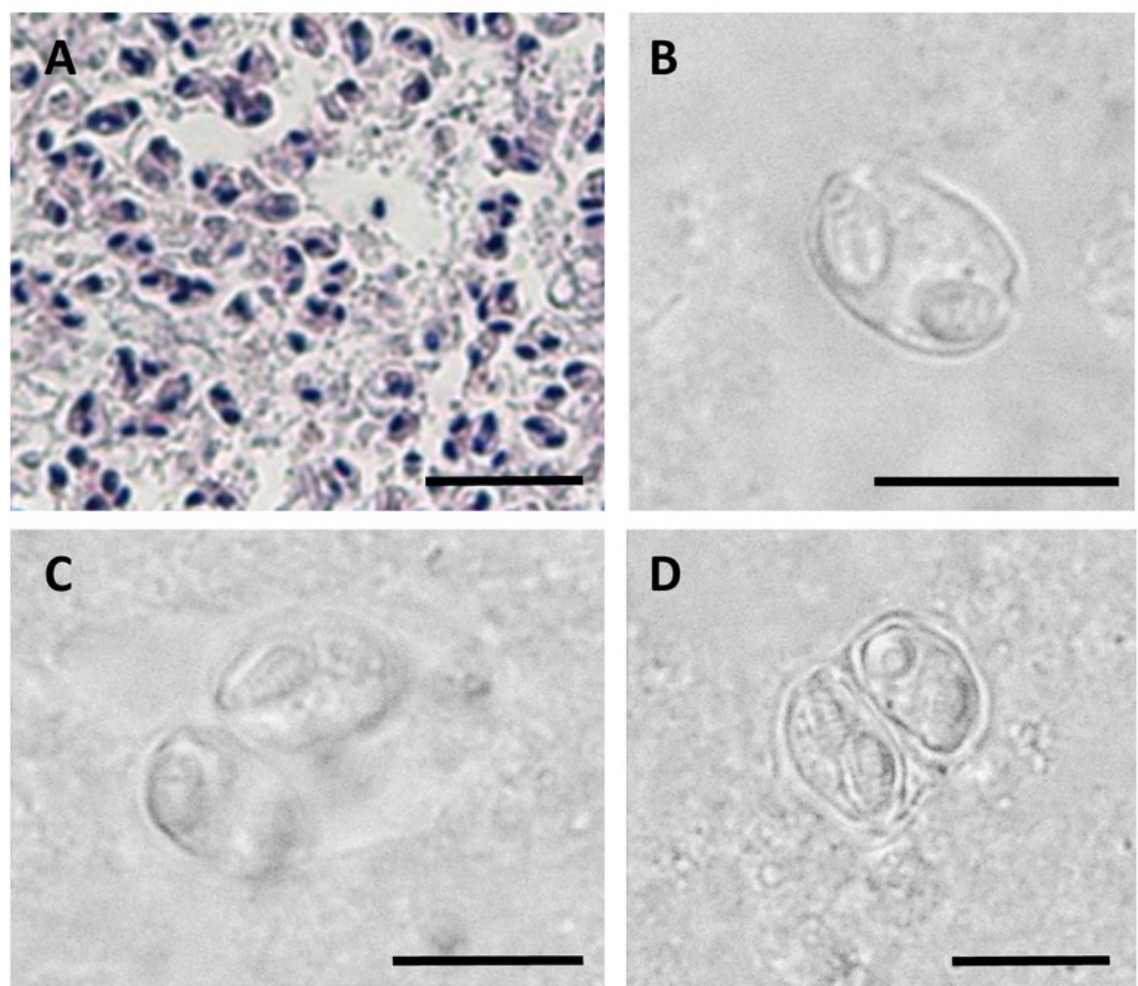
Figure 3

SEM of myxospores of Enteromyxum caesio n. sp

(A) Sutural view; note the smooth non striated valves, flush suture (black arrows) and valvular ridges (white arrows). (B) Valvular view; note the ridges (white arrows) at edge of each valve, adjacent to the polar capsules (white asterisks). (C) High magnification of the tip of the polar capsule detailing the capsular foramina. Scale bars $A \& B=3 \mu \mathrm{m}, \mathrm{C}=1 \mu \mathrm{m}$. 

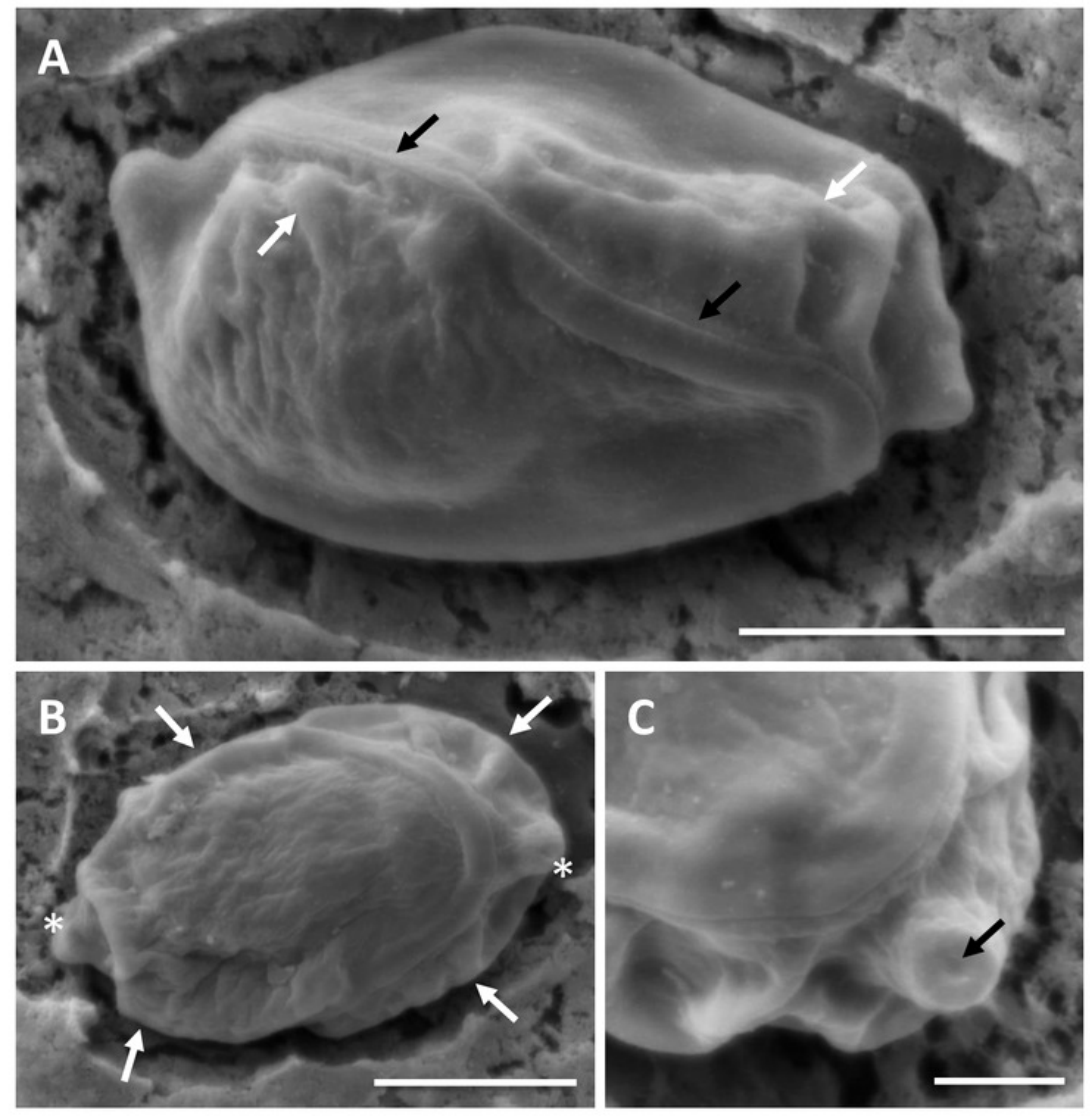


\section{Figure 4}

Trophozoites of Enteromyxum fugu , attached to the microvilli of the intestinal lining by pseudopodia.

(A) Large trophozoite containing a secondary cell, hyperinfected with a microsporidian spore

(white asterisk). (B) Immature trophozoite containing many mitochondria and developing microsporidians (white asterisks). (C) Close up of the pseudopodia from (B) detailing their attachment around the entire microvillus (white arrow). (e) enterocyte, $(\mathrm{m})$ mitochondria, (s) secondary cell. Scale bars $A \& B=2 \mu \mathrm{m}, C=1 \mu \mathrm{m}$. 

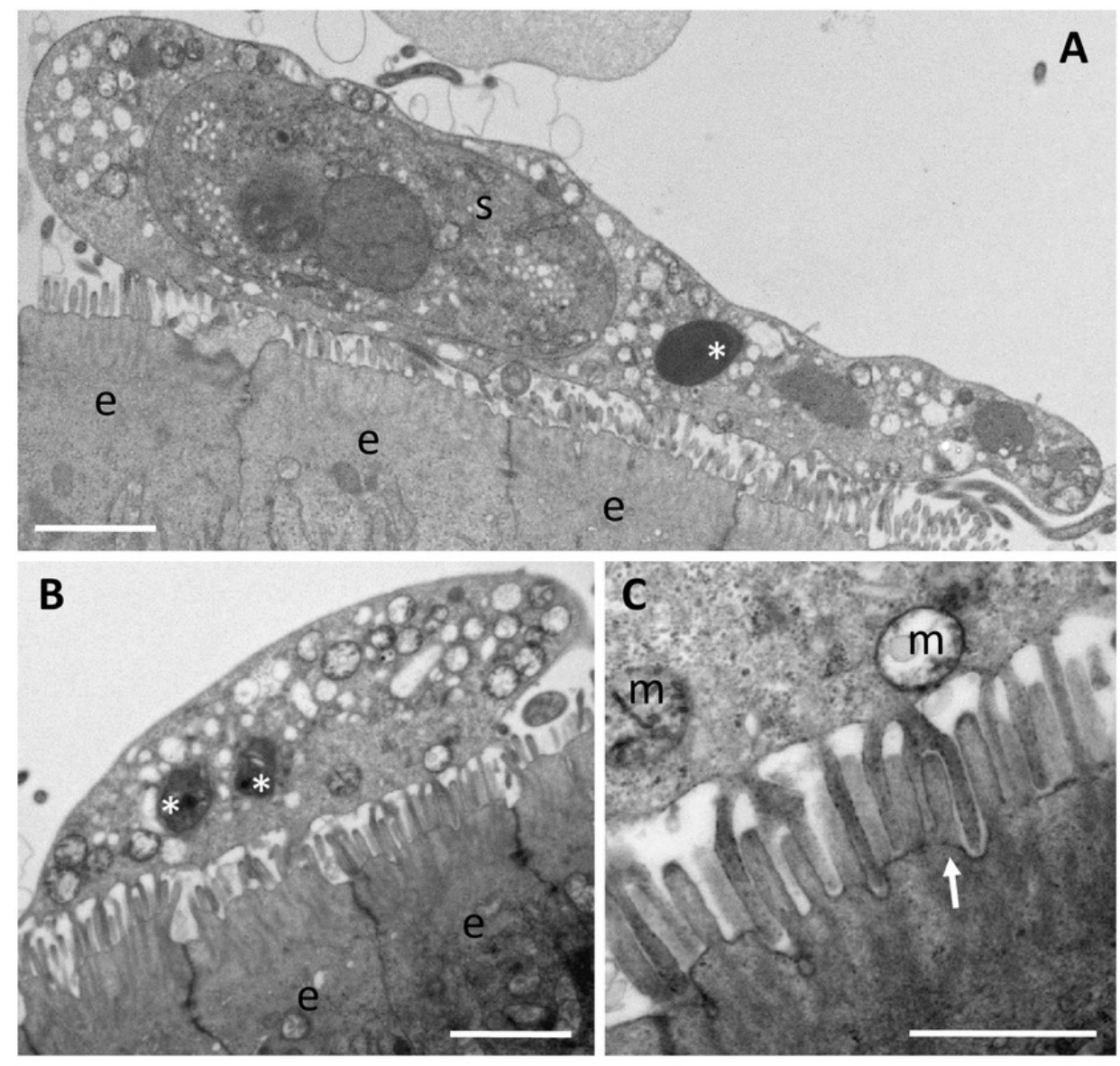


\section{Figure 5}

Maximum likelihood topology of the main clades of marine myxosporeans

The main marine myxosporean clades, shown in coloured boxes, are well supported from the relevant nodes (red asterisks). However, the relative grouping of these robust clades is not supported, apart from the most basal Ceratomyxa clade. Enteromyxum caesio n. sp. is robustly grouped within the Enteromyxum clade. Chloromyxum riorajum was used as an outgroup. Accession numbers are given after taxon names and numbers at the nodes represent bootstrap support from 1000 resamplings. (MUC) Marine Urinary Clade. 


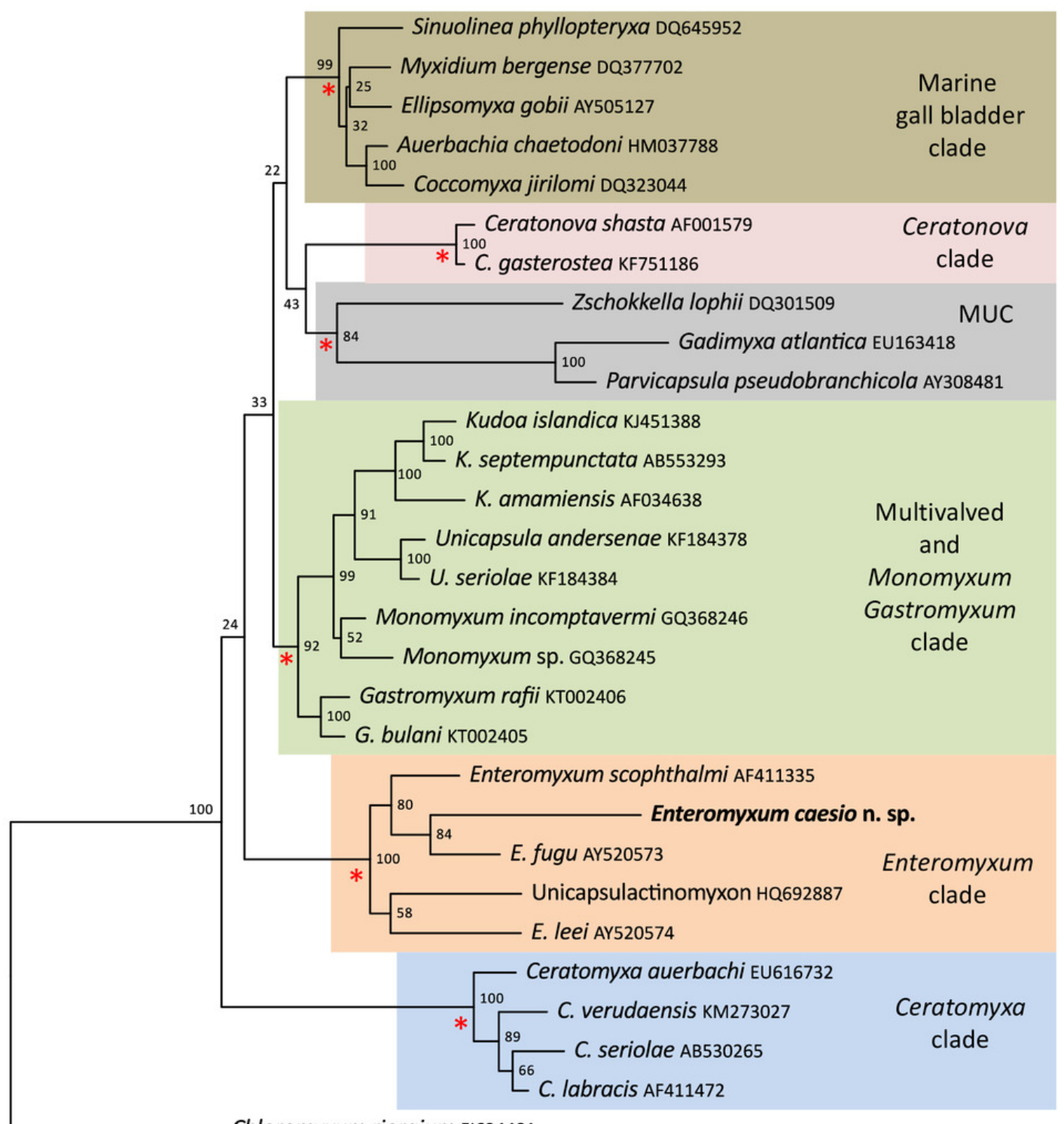

Chloromyxum riorajum FJ624481

0.1 